\title{
The Recurrence of Leprosy Reactional Episodes Could be Associated with Oral Chronic Infections and Expression of Serum IL-1, TNF- $\alpha$, IL-6, IFN- $\gamma$ and IL-10
}

\author{
Ana Carolina F. MOTTA ${ }^{1}$ \\ Renata Bazan FURINI ${ }^{1}$ \\ João Carlos Lopes SIMÃO ${ }^{1}$ \\ Maria Aparecida Nunes FERREIRA ${ }^{1}$ \\ Marilena C. KOMESU ${ }^{2}$ \\ Norma T. FOSS ${ }^{1}$
}

\begin{abstract}
${ }^{1}$ Division of Dermatology, School of Medicine of Ribeirão Preto, University of São Paulo, Ribeirão Preto, SP, Brazil ${ }^{2}$ Department of Morphology, Stomatology and Physiology, Ribeirão Preto Dental School, University of São Paulo, Ribeirão Preto, SP, Brazil
\end{abstract}

\begin{abstract}
The aim of this study was to determine whether the presence of leprosy reactional episodes could be associated with chronic oral infection. Thirty-eight leprosy patients were selected and divided into 2 groups: group I - 19 leprosy patients with oral infections, and group II - 19 leprosy patients without oral infections. Ten patients without leprosy, but presenting oral infections, were assigned to the control group. Leprosy patients were classified according to Ridley and Jopling classification and reactional episodes of the erythema nodosum type or reversal reaction were identified by clinical and histopathological features associated with serum IL-1, TNF- $\alpha$, IL- 6 , IFN- $\gamma$ and IL-10 levels. These analyses were performed immediately before and 7 days after the oral infection elimination. Patients from group I presenting oral infections reported clinical improvement of the symptoms of reactional episodes after dental treatment. Serum IL-1, TNF- $\alpha$, IL-6, IFN- $\gamma$ and IL-10 levels did not differ significantly before and after dental treatment as determined by the Wilcoxon test ( $>0.05)$. Comparison of the 2 groups showed statistically significant differences in IL- 1 and IL- 6 at baseline and in IL-1, IL- 6 and IL-10 on the occasion of both collections 7 days after therapy. Serum IL-6 and IL-10 levels in group I differed significantly at baseline compared to control (Mann-Whitney test; $\mathrm{p}<0.05$ ). These results suggest that oral infection could be involved as a maintenance factor in the pathogenesis of leprosy reactional episodes.
\end{abstract}

Key Words: leprosy reaction, Mycobacterium leprae, oral infection, focal infection, cytokines.

\section{INTRODUCTION}

Reactional episodes represent a serious problem in the course of leprosy since they can be responsible for much of the permanent nerve damage, leading to disability and deformities (1). There is an urgent need to understand the pathogenesis of these alterations in order to determine which patients may be considered at risk. These episodes represent an exacerbation of the inflammatory process that can occur before, during and after leprosy treatment $(2,3)$. There are mainly two well recognized types of reaction, reversal reaction $(R R)$ and erythema nodosum leprosum (ENL). RR may be due to an increase in the cell-mediated response to Mycobacterium leprae characterized by a Th1 response. ENL is a systemic inflammatory process with clinical manifestations of an acute inflammatory reaction characterized by intralesional neutrophilic infiltration and by a Th2 response $(3,4)$.

As both types of reaction are accompanied by an increased release of the inflammatory markers $(5,6)$, it is reasonable to consider the possibility that these episodes may be associated with an infectious process, such as a dental abscess and periodontal diseases which can induce

Correspondence: Dra. Ana Carolina Fragoso Motta, Departamento de Clínica Médica, Faculdade de Medicina de Ribeirão Preto, USP, Avenida Bandeirantes, 3900, 14049-900 Ribeirão Preto, SP, Brasil. Tel/Fax: +55-16-3633-0236. e-mail: anacfm@usp.br 
over-stimulation of the host immune system through the release of numerous inflammatory markers, including cytokines, acute-phase proteins and chemokines (7-9).

The aim of this study was to determine whether the presence of reactional leprosy episodes could be associated with dental and periodontal infection, and to determine serum IL-1, TNF- $\alpha$, IL- 6 , IFN- $\gamma$ and IL-10 levels before and after the oral infections elimination in leprosy patients.

\section{MATERIAL AND METHODS}

\section{Patients}

Leprosy patients with and without oral infection (OI) participated in the study before, during or after specific leprosy treatment (multidrug therapy-WHO). Forty-four patients were selected at the Leprosy Clinics of the School of Medicine of Ribeirão Preto, University of São Paulo, and were divided into 2 groups: group I consisted of leprosy patients presenting some oral infections, and group II consisted of leprosy patients without oral infections. The diagnosis of leprosy was made based on clinical and histopathological findings, on the Ridley and Jopling classification (1966) (10), bacilloscopy, biopsy, and the determination of antibodies to phenolic glycolipid-1 (anti-PGL-1). The oral infections considered were: periodontal diseases (PD), irreversible pulpitis (IP), pulpal necrosis (PN) and inflammatory periapical lesions (IPL). Inclusion criteria were: at least one tooth with probing pocket depth $>4 \mathrm{~mm}$ at 2 sites, or at least one tooth with some symptomatic or asymptomatic dental diseases (IP, PN or IPL). The control group consisted of ten patients without leprosy presenting oral infections. Subjects were excluded if they presented a coexisting local or systemic infection or diabetes mellitus, and if they had received antimicrobial treatment for oral infections in the previous 6 months. The trial was approved by the local Research Ethics Committee and all subjects gave written informed consent to participate.

\section{Clinical Data Collection}

An experienced examiner (ACFM) used a manual periodontal probe to perform the periodontal measurement, which were recorded at 6 sites per tooth at baseline and at 7 days after periodontal treatment. The parameters recorded for PD diagnosis were probing pocket depth
(PPD), bleeding on probing (BOP), suppuration (SUP), and the presence or absence of biofilm at 6 sites per tooth [plaque index (PI)]. IP was characterized by pulpal inflammation with clinical pulp exposure associated with positive pulpal sensitivity to testing with a cryogenic spray, PN was determined by loss of pulpal sensitivity without radiographic evidence of periapical alveolar loss, and IPL was characterized by loss of pulpal sensitivity associated with radiographic evidence of periapical alveolar loss. Radiological examination consisted of standardized periapical radiographs.

\section{Study Design and Clinical Response}

After the diagnosis of leprosy and of oral disease, both study groups (I and II) were instructed about oral hygiene techniques and supragingival prophylaxis. The patients were reexamined 7 days after completion of the dental and/or periodontal treatment (group I) or dental prophylaxis (group II). The criteria of analysis were based on clinical features such as the presence of reactional episodes, laboratory exams such as blood counts, urinary assay, and serum quantification of IL-1, TNF- $\alpha$, IL-6, IFN- $\gamma$ and IL-10 level by ELISA. Serum cytokine concentrations obtained for group I and II were compared with the data obtained for the control group. Care was taken to maintain the same systemic treatment during the analysis in order to avoid variables related to drugs. The severity of reactional episodes was determined on the basis of symptoms, amount of clinical skin manifestations and peripheral nerve involvement presented by each patient between the 2 collections.

\section{Periodontal Treatment (PT)}

Leprosy subjects with PD were treated by nonsurgical periodontal therapy, which consisted of sessions of scaling and root planning (SRP) conducted over a maximum of 6 weeks using ultrasonic instrumentation (PROFI II Ceramic; Dabi Atlante, Ribeirão Preto, SP, Brazil) and standard Gracey curettes (Hu-Friedy Instruments, Chicago, IL, USA). Patients were followed up every 7 days for 1 month when all them were reevaluated. Oral hygiene instructions were reinforced at each visit.

\section{Endodontic Treatment (ET)}

Endodontic therapy was carried out in a single or double session based on diagnosis made by manual 
instrumentation (K-Flex Files; Sybron-Endo, Glendora, CA, USA) and a combination of lateral condensation technique and sealer (Sealapex; Sybron-Endo, CA, USA). The criteria for the evaluation of treatment success were based on inflammation signs and symptoms, complemented with periapical radiographic analysis every 3 month for IPL cases.

\section{Statistical Analysis}

Mean PPD, BOP, SUP and missing teeth were calculated for each patient from group I and II, and serum IL-1, TNF- $\alpha$, IL-6, IFN- $\gamma$ and IL-10 were calculated for each group (I, II and control). The results of the three groups were compared by the Mann-Whitney test and baseline values (before) were compared to those obtained after 7 days (only for groups I and II) by the Wilcoxon rank-sum test using the GraphPad Prism software (GraphPad Inc., San Diego, CA, USA). Significance was set at $\mathrm{p}<0.05$.

\section{RESULTS}

\section{Characteristics of the Study Population}

Six of the initial 44 leprosy subjects were excluded from the study, four of them because they did not conclude the dental treatment, and the other two because of a worsening of their general condition. The final enrolled sample consisted of 38 leprosy patients ( 29 men and 9 women, mean \pm SD age $43.92 \pm 2.12$ years; range 18-81 years) before, during or after specific leprosy treatment (multidrug therapy-WHO), and 10 healthy patients, as a control group. Group I consisted of 19 leprosy patients (13 men and 6 women, mean age $45.05 \pm 6.3$ years; range $18-72$ years) presenting some oral infections: 7 patients presented dental diseases (IP, PN and IPL), 3 presented PD, and 9 presented a combination of dental diseases (PN and IPL) and PD. In this group, 9 patients presented lepromatous leprosy (LL), 5 were borderline lepromatous (BL), 3 borderline borderline (BB), and 2 borderline tuberculoid (BT). Group II consisted of 19 patients (16 men and 3 women; mean age $42.8 \pm 13.4$ years; range 21-81 years) without oral infections. In this group, 4 patients presented LL, $1 \mathrm{BL}, 1 \mathrm{BB}, 9 \mathrm{BT}$ and 4 presented the tuberculoid (TT) form. The control group consisted of 10 male patients (mean age $45.7 \pm 8.48$ years; range $42-58$ ) presenting oral infections: 3 patients with dental diseases (IP and
PN), 3 with $\mathrm{PD}$, and 4 with a combination of dental diseases (IP) and PD.

\section{Clinical Parameters}

Fifteen out of 19 (78.9\%) patients in group I presented ENL at the time of diagnosis, 3 (15.8\%) patients had reversal reaction (2 BT and $1 \mathrm{BL}$ patients) and only one $(5.3 \%)$ patient did not present reactional episodes.

After dental and/or periodontal treatment, 68.4\% (13/19) of group I patients presented clinical improvement of reactional episodes, as determined by a decrease of skin lesions and symptoms whereas no clinical alteration was verified in the group II.

\section{Periodontal and Dental Parameters}

All periodontal and dental parameters were compared at baseline and 7 days after therapy in each group (intragroup comparisons) and between groups (intergroup comparisons) (Table 1). For group I, the periodontal treatment protocol resulted in a statistically significant improvement in all variables analyzed after 7 days. There was also a reduction of PPD, PI and BOP of $4.3 \mathrm{~mm}, 30 \%$ and $19.4 \%$, respectively, and no SUP was detected after 7 days. The number of teeth with ET increased and the number of remaining teeth decreased after 7 days of therapy. For group II, there was a PI and BOP reduction of $11.3 \%$ and $9.9 \%$, respectively, and no significant differences ( $p>0.05$ ) were found for the other parameters. Group comparison showed a statistically significant difference between PI values at baseline $(p=0.027)$ and number of teeth with ET 7 days after therapy $(\mathrm{p}=0.035)$.

\section{Inflammatory Markers}

Serum IL-1, TNF- $\alpha$, IL-6, IFN- $\gamma$ and IL-10 levels did not differ significantly before and after dental treatment in group I even though they tended to change after dental and periodontal treatment. No differences were observed between the 2 collections regarding clinical findings or any monitored mediators in group II. In basal conditions there were significant differences between the groups for IL- 1 and IL-6, and 7 days after therapy there were significant differences between the groups for IL-1, IL-10 and IL-6. Serum IL-6 and IL-10 levels in group I differed significantly at baseline compared to control (Figs. 1-5). 


\section{DISCUSSION}

In this study, an attempt was made to clarify whether chronic OI could represent a maintaining factor in reactional leprosy episodes. A relationship between focal infection and dermatoses such as psoriasis (11) and atopic dermatitis (12) has been reported but none concerning reactional episodes. It was observed that ENL was more frequent in patients with OI (78.9\%) than in patients with the absence of OI (15.2\%). This may have

Table 1. Clinical parameters (mean \pm SD) monitored at baseline and 7 days after oral infection therapy.

\begin{tabular}{|c|c|c|c|}
\hline Variable & Group I & Group II & $\mathrm{p}$ value** \\
\hline \multicolumn{4}{|c|}{ Sites with PPD $>4 \mathrm{~mm}(\mathrm{n})$} \\
\hline Baseline & $4.68 \pm 1.09$ & $0.0 \pm 0.0$ & $<0.0001$ \\
\hline 7 days after therapy & $0.36 \pm 0.21$ & $0.0 \pm 0.0$ & $<0.0001$ \\
\hline $\mathrm{p}$ value & 0.0001 & - & \\
\hline \multicolumn{4}{|l|}{$P I(\%)$} \\
\hline Baseline & $73.61 \pm 20.19$ & $48.71 \pm 30.98$ & 0.027 \\
\hline 7 days after therapy & $43.55 \pm 21.63$ & $37.38 \pm 24.13$ & 0.492 \\
\hline $\mathrm{p}$ value* & 0.0001 & $<0.0001$ & \\
\hline \multicolumn{4}{|l|}{$B O P(\%)$} \\
\hline Baseline & $52.29 \pm 28.62$ & $35.94 \pm 27.16$ & 0.118 \\
\hline 7 days after therapy & $32.83 \pm 25.26$ & $26.02 \pm 19.02$ & 0.492 \\
\hline p value* & 0.0001 & $<0.0001$ & \\
\hline \multicolumn{4}{|l|}{$S U P(\%)$} \\
\hline Baseline & $7.73 \pm 3.29$ & $0.0 \pm 0.0$ & $<0.0001$ \\
\hline 7 days after therapy & $0.0 \pm 0.0$ & $0.0 \pm 0.0$ & - \\
\hline $\mathrm{p}$ value* & $<0.0001$ & - & \\
\hline \multicolumn{4}{|l|}{ Teeth with ET (n) } \\
\hline Baseline & $0.15 \pm 0.15$ & $0.10 \pm 0.07$ & 0.804 \\
\hline 7 days after therapy & $0.78 \pm 0.23$ & $0.10 \pm 0.07$ & 0.035 \\
\hline $\mathrm{p}$ value* & 0.007 & 0.988 & \\
\hline \multicolumn{4}{|l|}{ Remaining teeth (n) } \\
\hline Baseline & $19.21 \pm 10.17$ & $18.63 \pm 11.79$ & 0.804 \\
\hline 7 days after therapy & $16.21 \pm 10.79$ & $18.63 \pm 11.79$ & 0.568 \\
\hline $\mathrm{p}$ value* & $<0.0001$ & 0.988 & \\
\hline
\end{tabular}

*Intragroup (horizontal) and $* *$ intergroup (vertical) comparisons. PPD = probing pocket depth; $\mathrm{PI}=$ plaque index; $\mathrm{BOP}=$ bleeding on probing; SUP $=$ suppuration; $\mathrm{ET}=$ endodontic treatment. been due to the fact the elevation in inflammatory marker expression by cells in the presence of OI can cause a spill-over of these markers into the circulation where they can act as a maintaining factor in leprosy reactions, as described for other diseases $(9,12)$.

Considering that bacteremia is resolved within a few hours after dental procedures $(13,14)$, it was assumed that collections before and 7 days after resolution of OI were appropriate. In addition, this period was adopted to minimize the risk of reinfection especially with respect to periodontal diseases, and to avoid the influence of other infections. After OI treatment, there was an improvement of clinical symptoms in $68.4 \%$ (13/19) of patients from group I, and there was improvement in all of the periodontal clinical parameters monitored.

Although oral infections are a multifactorial inflammatory condition, it was expected that patients from group I could have high production of IL-1, IL-6, TNF- $\alpha$ and IFN- $\gamma$, and low production of IL-10 at baseline when compared to 7 days after therapy. However, no significant difference was found between these phases. It is likely that the 7-day period after OI treatment was not sufficient to determine a decrease of serum IL- 1 , TNF- $\alpha$, IL-6, IFN- $\gamma$ and an increase of IL-10 levels. On the other hand, it is well known that the serum concentrations of cytokines may suffer interference from many other serum factors and from several cell types.

There was a significantly higher level of IL- 1 and IL-6 in patients with OI (group I) than in patients without these infections (group II) at baseline ( $p=0.03$ and $p<0.0001$, respectively), and significantly difference of IL-1, IL-10 and IL-6 between the groups 7 days after therapy $(p=0.028, p=0.041$ and $\mathrm{p}=0.01$, respectively). No statistically significant difference in serum TNF- $\alpha$ and IFN- $\gamma$ levels was observed between the 2 groups at baseline and after OI therapy. It may be assumed that the serum cytokines, as evaluated in this study, can be interesting diagnostic biomarkers, although its significance should be considered with caution since they are general inflammatory marker.

IL-6 and IL-10 levels of healthy patients (control group) were significantly 


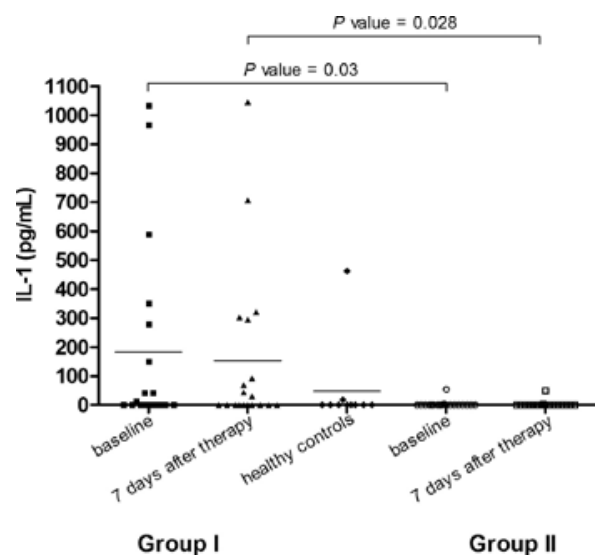

Figure 1. IL-1 levels in serum from leprosy patients presented oral chronic infections (group I), leprosy patients without oral infection (group II) before and after oral infection therapy and healthy controls.

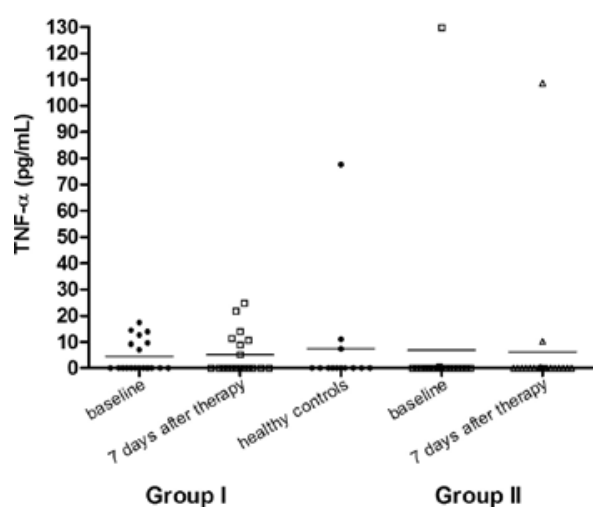

Figure 2. TNF- $\alpha$ levels serum from leprosy patients presented oral chronic infections (group I), leprosy patients without oral infection (group II) before and after oral infection therapy and healthy controls.

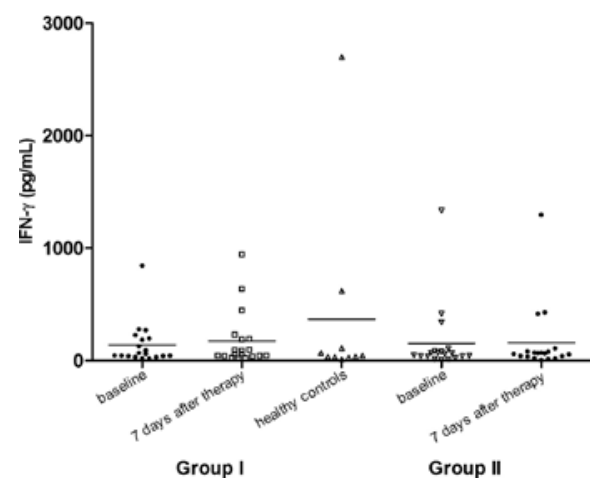

Figure 4. IFN- $\gamma$ levels serum from leprosy patients presented oral chronic infections (group I), leprosy patients without oral infection (group II) before and after oral infection therapy and healthy controls. higher than those leprosy patients with OI (group I) These findings demonstrate that OI can induce overexpression of inflammatory markers even in the absence of systemic inflammatory diseases. On the other hand, the difference detected in IL-10 demonstrates that reactional episodes of leprosy plus oral infections can increase the induction potential of a cytokine response.

IL-1 plays an important role in several chronic diseases and it is produced by mononuclear phagocytes induced by bacterial products, by other cytokines and by many other cell types, such as neutrophils, epithelial cells and endothelial cells. When secreted in larger amounts, as verified in group I, IL-1 induces systemic effects of inflammation (15). The serum IL levels in patients with

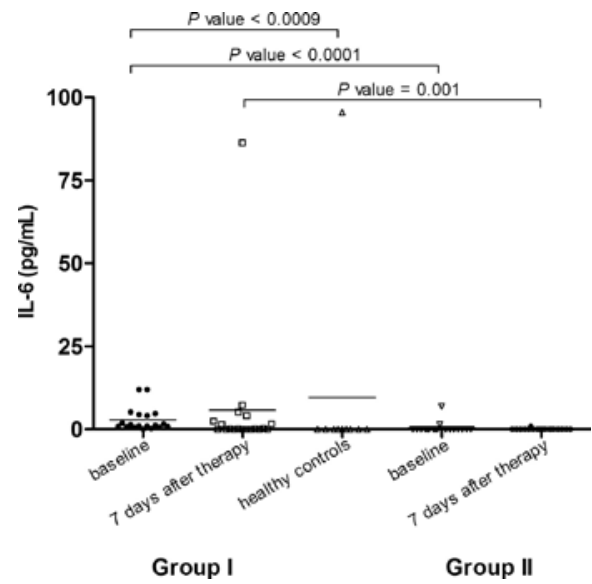

Figure 3. IL-6 levels serum from leprosy patients presented oral chronic infections (group I), leprosy patients without oral infection (group II) before and after oral infection therapy and healthy controls.

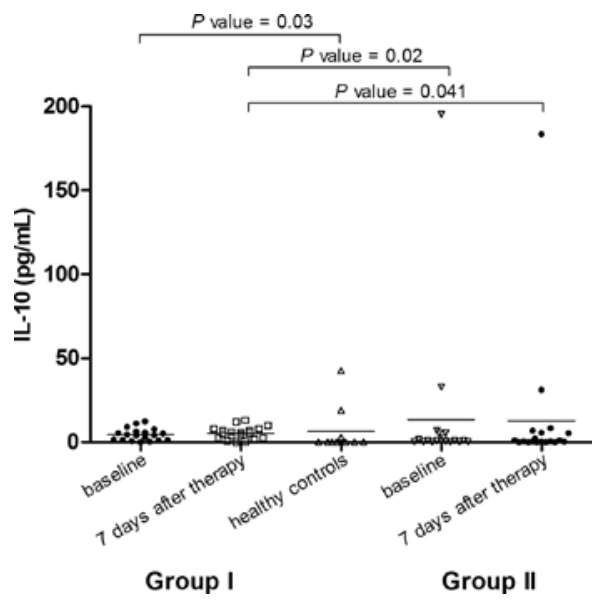

Figure 5. IL-10 levels serum from leprosy patients presented oral chronic infections (group I), leprosy patients without oral infection (group II) before and after oral infection therapy and healthy controls. 
OI were higher than those in the ones without OI. Thus it can be explained the high occurrence of reactional episodes in the patients from group I when compared to the patients from group II.

IL-6 acts in both innate and adaptative immune responses and its main functions involve the stimulation of haematopoiesis and the production of acute-phase proteins by hepatocyte and B-lymphocyte growth (16). The role of IL- 6 in the pathogenesis of oral infections, such as periodontal diseases and dental abscesses has been supported by studies $(9,17,18)$ showing that IL-6 levels are elevated in serum and tissues of patients with these infections. However, the oral therapy in the study did not show changing in IL-6 serum levels.

IL-10 has been considered an anti-inflammatory cytokine that can regulate the Th1 pattern of the cellular immune response, however, the biological activity of the cytokine seems to exhibit an immunoregulatory activities $(19,20)$. In this study, it was found that patients with OI exhibited decreased serum IL-10 levels when compared to patients without OI.

As most patients with OI (78.9\%) presented reactional episodes and showed higher serum IL-1, IL-6 and IL-10 levels than those without OI, the findings of the present study suggest that OI might have stimulated the inflammatory reaction. Studies with a larger sample are necessary to support this observation because dental treatment may improve the care of leprosy patients in order to prevent disability caused by leprosy reactions.

\section{RESUMO}

O objetivo deste estudo foi determinar se os episódios reacionais da hanseníase podem estar associados a infecções orais crônicas. Trinta e oito pacientes com hanseníase foram selecionados e divididos em dois grupos: grupo I- 19 pacientes com hanseníase apresentando infecções orais, e grupo II - 19 pacientes com hanseníase sem infecções orais. Os pacientes foram classificados, quanto à forma clínica da doença, de acordo com Ridley and Jopling, e os episódios reacionais, tipo eritema nodoso e reação reversa, foram identificados pelas características clínicas, histopatológicas associadas à quantificação no soro de IL-1, TNF- $\alpha$, IL-6, IFN- $\gamma$ e IL-10. Estas analises foram realizadas imediatamente antes e 7 dias após a resolução dos focos de infecção. Pacientes do grupo I aprentando infecções orais relataram melhora clínica dos sintomas dos episódios reacionais após o tratamento odontológico. Os níveis séricos de IL- $1, \mathrm{TNF}-\alpha$, IL-6, IFN- $\gamma$ e IL-10 não diferiram significantemente antes e após o tratamento odontológico, como determinado pelo teste Wilcoxon $(p>0,05)$. As comparações entre os grupos mostrou diferenças estatisticamente significantes nos níveis de IL-1 e IL-6 na coleta inicial e nos níveis de IL-1, IL-6 e IL-10 nas duas coletas 7 dias após o tratamento (teste Mann-Whitney; $p<0,05$ ).
Estes resultados sugerem que infecções orais estão envolvidas na patogênese dos episódios reacionais da hanseníase, como fatores mantenedores.

\section{ACKNOWLEDGEMENTS}

We thank the National Council for Scientific and Technological Development - CNPq (grant 154806/2006-4), The São Paulo State Foundation against Leprosy (grant 110) and the Foundation of Support to Teaching, Research and Assistance of HCFMRP-USP (FAEPA) for financial support, and Mr Mario Ignácio Neto for assistance with sample analysis.

\section{REFERENCES}

1. Jopling WH. Classification of reaction in leprosy. Leprosy Rev 1970;41:62-63.

2. Seghal VN, Sharma V. Reactions in leprosy - a prospective study of clinical, bacteriological, immunological and histopathological parameters in thirty-five Indians. J Dermatol 1988;15:412-419.

3. Rea TH, Modlin RL. Immunopathology of leprosy skin lesions. Semin Dermatol.1991;10:188-193.

4. Cuevas J, Rodríguez-Peralto JL, Carrillo R, Contreras F. Erythema nodosum leprosum: reactional leprosy. Sem Cutan Med Surg 2007;26:126-130.

5. Sarno EM, Grau GE, Vieira LM, Nery JA. Serum levels of tumor necrosis factor - alpha and interleukin 1 beta during leprosy reactional states. Clin Exp Immunol 1991;84:103-108.

6. Foss NT, de Oliveira EB, Silva CL. Correlation between TNF production, increase of plasma $\mathrm{C}$-reactive protein level and suppression of $\mathrm{T}$ lymphocyte response to concanavalin A during erythema nodosum leprosum. Int J Lepr Other Mycobact Dis 1993;61:218-226.

7. Hujoel PP, Drangsholt M, Spiekerman C, Hujoel PP, Drangsholt M, Spiekerman C, DeRoven TA. Pre-existing cardiovascular disease and periodontitis: a follow-up study. J Dent Res 2002;81:183191.

8. Jeffcoat MK, Geurs NC, Reddy MS, Cliver SP, Goldenberg RL, Hauth JC. Periodontal infection and preterm birth: results of a prospective study. J Am Dent Assoc 2001;132:875-880.

9. Marcaccini AM, Meschiari CA, Sorgi CA, Saraiva MC, de Souza AM, Faccioli LH, Tanus-Santos JE, Novaes AB, Gerlach RF. Circulating interleukin-6 and high-sensitivity C-reactive protein decrease after periodontal therapy in otherwise healthy subjects. J Periodontol 2009;80:594-602.

10. Ridley DS, Jopling WH. Classification of leprosy according to immunity: a five-group system. Int J Lepr Other Mycobact Dis 1966;34:255-273.

11. Mizutani H, Ohmoto Y, Mizutani T, Murata M, Schimizu M. Role of increased production of monocytes TNF-alpha, IL-1 beta and IL-6 in psoriasis: relation to focal infection, disease activity and responses to treatments. J Dermatol Sci 1997;14:145-153.

12. Igawa K, Nishioka K, Yokozeki H. Odontogenic focal infection could be partly involved in the pathogenesis of atopic dermatitis as exacerbating factor. Int J Dermatol 2007;46:376-379.

13. Heimdahl A, Hall G, Hedberg M, Sandberg H, Söder PD, Tunér K, Nord CE. Detection and quantification by lysis-filtration of bacteremia after different oral surgical procedures. J Clin Microbiol 1990;28:2205-2209.

14. Lockhart PB. An analysis of bacteremias during dental extractions: a double-blind, placebo-controlled study of chlorhexidine. Arch Intern Med 1996;156:513-520. 
15. Abbas AK, Lichtman AH, Pillai S. Cytokines. In: Cellular and molecular immunology. Abbas AK (Editor). 6th ed. Philadelphia: Saunders Elsevier; 2007. p. 267-301.

16. Emery P, Salmon M. The immune response 2. Systemic mediators of inflammation. British Journal of Hospital Medicine 1991;45:164-168.

17. O'Connell PAA, Taba Jr. M, Nomizo A, Foss Freitas MC, Suaid FA, Uyemura SA, Trevisan GL, Novaes Jr AB, Souza SLS, Palioto DB, Grisi MFM. Effects of periodontal therapy on glycemic control and inflammatory markers. J Periodontol 2008;79:774-783.

18. de Sá AR, Moreira PR, Xavier GM, Sampaio I, Kalapothakis E, Dutra WO, Gomez RS. Association of CD14, IL1B, IL6, IL10 and
TNFA functional gene polymorphisms with symptomatic dental abscesses. Int Endod J 2007;40:563-572.

19. Volk H, Asadullah K, Gallagher G, Sabat R, Grutz G. IL-10 and its homologs: important immune mediators and emerging immunotherapeutic targets. Trends in Immunology 2001;22:414-417.

20. Mocellin S, Marincola F, Rossi CR, Nitti D, Lise M. The multifaceted relationship between IL-10 and adaptative immunity: putting together the pieces of a puzzle. Cytokine Growth Factor Rev 2004;15:61-76.

Accepted April 20, 2010 